\title{
Psychological factors affecting COVID-19 vaccine hesitancy
}

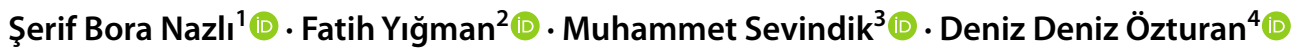

Received: 12 April 2021 / Accepted: 3 May 2021 / Published online: 14 May 2021

(c) Royal Academy of Medicine in Ireland 2021

\begin{abstract}
Background Vaccine hesitancy is an important public health problem.

Aims Identifying and understanding COVID-19 vaccine hesitancy may aid future public health messaging. This study, in which we planned to study the determinants of COVID-19 vaccine hesitancy, aims to reveal the relationship between "intolerance of uncertainty," "belief in conspiracy theories," and "COVID-19 phobia" with vaccine hesitancy.

Methods This is a cross-sectional study conducted during a COVID-19 outbreak. Participants were reached via various social media platforms and e-mailing lists for convenience. Data were collected with an online survey using SurveyMonkey application. "Intolerance of Uncertainty Scale (IUS-12)," "Conspiracy Mentality Scale (CMS)," and "COVID-19 Phobia Scale" were applied to 488 participants. Statistical significance level was considered $p<0.05$.

Results Four hundred eighty-eight people between the ages of 18 and 65 participated. Twenty-one participants were excluded from the analysis due to random marking and unreasonable filling times $(<10 \mathrm{~min})$. In this way, analyzes were made with 467 people. We found a positive correlation between the belief in conspiracy theories and vaccine hesitancy $(p<0.05)$. And also found that individuals with low fear of COVID-19 would hesitate about vaccination $(p<0.05)$.

Conclusions Vaccine hesitancy is an important public health problem, and it puts public health at risk, especially during the epidemic period we live in. Therefore, it is important to understand the psychological factors involved in vaccine hesitancy. It would be useful to look for ways to spread accurate information about the vaccine in a healthier way in this case.
\end{abstract}

Keywords Conspiracy theories · COVID-19 phobia · COVID-19 vaccine $\cdot$ Vaccine hesitancy

\section{Introduction}

Severe acute respiratory syndrome coronavirus disease 2019 (COVID-19) pandemic caused by coronavirus 2 (SARSCoV-2) was first detected in Wuhan, China, in December

Şerif Bora Nazlı

bosbora@yahoo.com

Fatih Yığman

dr.yigman@gmail.com

Muhammet Sevindik

muhammetsevindik_52@hotmail.com

Deniz Deniz Özturan

dr.denizdeniz@gmail.com

1 Psychiatry Department, Ankara Dışkapı Traning and Research Hospital, Ankara, Turkey

2 Psychiatry Department, Ufuk University, Ankara, Turkey

3 Psychiatry Department, Ordu University Traning and Research Hospital, Ordu, Turkey

4 Psychiatry Department, Ordu University, Ordu, Turkey
2019. It spread worldwide within 1 month of the emergence of the novel coronavirus. The World Health Organization (WHO) declared COVID-19 a pandemic worldwide on 11 March 2020 [1]. Physical distance and quarantine measures have been put in place to slow the spread of the virus around the world, protect the community, and manage healthcare demand and delivery since there is no effective treatment or vaccine [2]. However, the need for an approved vaccine has become indisputable to protect society from this virus and save the economy from ongoing interruptions and damage.

The concept of "vaccine hesitancy" is seen by the World Health Organization (WHO) as "one of the top ten threats to global health." It is wondered whether the COVID-19 outbreak, which can be defined as a global and emergency situation, will solve the vaccine rejection problem that is worrying for public health for the last few decades [3]. Most of the current literature on vaccine hesitancy and resistance focuses on the clear causes individuals exhibit against a particular vaccine or vaccination programs in general [4]. Identifying psychological processes that distinguish vaccine-hesitant 
and resistant individuals from vaccine-sensitive individuals will be a guiding approach [5]. This approach may also provide the opportunity to adapt public health messages in accordance with the psychological tendencies of these individuals [6]. To date, many psychological structures have been investigated in relation to vaccine hesitancy. For example, altruistic beliefs [7]; personality traits neuroticism and conscientiousness [8]; conspiracy, religious, and paranoid beliefs [9]; distrust of authorized members of society such as government officials, scientists, and healthcare professionals have been associated with negative attitudes towards vaccines [12].

Vaccine hesitancies tend to increase overall even though it varies between countries [9]. It is important to reveal the determinants of vaccine hesitancy considering the increase in conspiracy theories about COVID-19 [10, 11]. Determining, understanding, and addressing vaccine acceptance, vaccine hesitancy, and vaccine resistance for COVID-19 are important steps to ensure the rapid and necessary use of a final vaccine $[4,12]$.

This study, in which we planned to study the determinants of COVID-19 vaccine hesitancy, aims to reveal the relationship between "intolerance of uncertainty," "belief in conspiracy theories," and "COVID-19 phobia" with vaccine hesitancy. We hypothesized that individuals who believe in conspiracy theories and have a low tolerance to uncertainty would have increased coronavirus vaccine hesitancy/rejection considering that vaccine hesitancy determinants should be revealed because vaccine hesitancy/rejection is an obstacle to controlling outbreaks. Individuals with low fear of COVID-19 will hesitate about vaccination. This study aims to examine the extent to which COVID-19 phobia, belief in conspiracy theories, and intolerance of uncertainty are decisive in vaccine hesitancy.

It would be useful to identify distinguishing psychological factors of individuals who are hesitant and resistant to the vaccine. In this way, the issue of "vaccine rejection" as a public health problem can be further clarified and actions for public health can focus on more targets. The problems in front of vaccination, which is the most important weapon in the fight against the pandemic, can be overcome.

\section{Methods}

\section{Participants and procedure}

This is a cross-sectional study conducted during a COVID19 outbreak. Participants were reached via various social media platforms and e-mailing lists for convenience. Surveys were administered through "SurveyMonkey," a platform that allows them to be distributed and analyzed on the web. The demographic characteristics of the respondents include whether they have been infected with COVID-19 before, whether they are ready to get the COVID-19 vaccine, and the "Intolerance of Uncertainty Scale (IUS-12)," "Conspiracy Mentality Scale (CMS)," and "COVID-19 Phobia Scale."

Four hundred eighty-eight people between the ages of 18 and 65 participated between March and April 2021. Twenty-one participants were excluded from the analysis due to random marking and unreasonable filling times (<10 min). In this way, analyses were made with 467 people. All participants were informed about the study, and the participants were included in the study voluntarily. Ethics committee approval was received from Ordu University.

\section{Scales}

\section{Intolerance of uncertainty scale}

It was observed that 12 items were collected in two subscales (prospective anxiety and debilitating anxiety) consistent with the original form in the confirmatory factor analysis applied for the construct validity of the scale $\left(\chi^{2}=147.20, \mathrm{SD}=48, \mathrm{RMSEA}=0.073, \mathrm{CFI}=0.95\right.$, $\mathrm{IFI}=0.95, \mathrm{GFI}=0.94, \mathrm{SRMR}=0.046)$. Factor loads of the scale were ranked between 0.55 and 0.87 , Cronbach's alpha consistency coefficient was found to be 0.88 for the whole scale, 0.84 for the prospective anxiety subscale, and 0.77 for the debilitating anxiety subscale. The test-retest correlation coefficient was found to be 0.74 ; it was also seen that the adjusted item-total correlations of the scale were ranked between 0.42 and 0.68 [13].

\section{Conspiracy mentality scale}

Bruder and Manfred (2009) collected data from Germany, Britain, and Turkey with a conspiracy theory scale consisting of 38 items related to conspiracy theories [14]. Bruder et al. (2013) used this data to define 5 items of the scale consisting of 38 items as Conspiracy Mentality Scale (CMS) and the remaining 33 items as items that measure believing in specific conspiracy theories [15]. Participants were asked to indicate how much they agreed with the items given in the scales on 11-point Likert type scales $(0 \%=$ absolutely no, $100 \%=$ absolutely yes $)$, and the 5 items mentioned in this study, which was previously conducted, were grouped separately. The obtained Conspiracy Mentality Scale (CMS) was found to be 0.72 for $\alpha$ reliability for the Turkish version. The remaining 33 items measure believing in specific conspiracy theories generally [16]. 


\section{COVID-19 phobia scale}

The COVID-19 Phobia Scale is a scale that can be used to measure feelings such as fear, anxiety, and related behavior changes during the COVID-19 pandemic. Item-total item analyses were performed with 1243 subjects in the permeability and reliability study. It consists of a total of 4 subscales and 22 items: worry, mood, reassurance seeking/precaution, and avoidance subscales. The Cronbach's alpha coefficient, which shows internal consistency, was measured as 0.84 , and the internal consistency coefficients of the subscales ranged from 0.60 to 0.91 [17].

\section{Vaccine conspiracy beliefs scale}

In addition, an additional questionnaire was created by the study team from social media accounts using the 5 most popular conspiracy theories related to vaccines in Turkey in order to have a parallel quality to the Conspiracy Mentality Scale.

\section{Statistical analysis}

The research data was uploaded and evaluated on a computer environment via "SPSS (Statistical Package for Social Sciences) for Windows 15.0 (SPSS Inc., Chicago, IL)" software. Descriptive statistics were presented as mean \pm standard deviation (minimum-maximum), frequency distribution, and percentage. The Pearson's chi-square test was used to evaluate categorical variables. The suitability of the variables for normal distribution was examined using visual (histogram and probability graphs) and analytical methods (Kolmogorov-Smirnov Test/Shapiro-Wilk Test). The Kruskal Wallis Test was used as the statistical method in the statistical significance between the four independent groups for the variables found not to comply with the normal distribution. Bonferroni correction was applied in post hoc binary comparisons of the source of the difference when a significant difference was detected. The relationship between the variables was evaluated by the Spearman's correlation test. The correlation coefficient was considered "weak" between 0 and 0.30 , "moderate" between 0.31 and 0.70 , and "strong" between 0.71 and 1.00. Statistical significance level was considered $p<0.05$.

\section{Results}

A total of 467 individuals over the age of 18 who agreed to participate and who could give complete answers to the questions in the data collection form were examined within the study's scope. Some descriptive characteristics of the individuals examined are given in Table 1.
The participants mean age included in the study was $35.8 \pm 9.1(\min 18-\max 67)$ years, and $55.9 \%(n=261)$ were female. $63.2 \%(n=295)$ of respondents were married, $34.5 \%$ $(\mathrm{n}=161)$ were single, and the remaining $2.4 \%(n=119)$ were divorced, widowed, or separated. $52.2 \%(n=244)$ of the participants had children. The mean number of children of the participants with children was $1.7 \pm 0.8$ (min $1-\max 4)$. Physicians were in the first place with $38.5 \%(n=180)$, followed by teachers with $9.9 \%(n=46)$, and assistant healthcare personnel with $9.4 \%(n=44)$ considering the professions of the participants. The least identified professional groups were engineering with $4.1 \%(n=19)$, dentistry with $2.8 \%(n=13)$, and faculty membership with $2.6 \%(n=12)$ (Table 1$)$.

Some characteristics of the participants related to COVID-19 are shown in Table 1.

$17.1 \%(n=80)$ of participants included in the study had previously experienced COVID-19. Of these 80 participants, 93.8\% $(n=75)$ received outpatient treatment, 3.8\% $(n=3)$ received inpatient treatment, and the remaining $2.5 \%(n=2)$ received inpatient treatment in intensive care unit (ICU). $13.5 \%(n=63)$ had first-degree relatives or close friends dying from COVID-19 whereas $37.0 \%(n=173)$ of the participants had first-degree relatives suffering from COVID-19 (Table 1).

Attitudes of participants towards the COVID-19 vaccine are presented in Table 2. 44.1\% $(n=206)$ of the respondents examined stated that they trusted the positive effects of the vaccine and wanted to get vaccinated, $40.9 \%(n=191)$ stated that they were undecided about the positive effects of the vaccine but wanted to get vaccinated, $8.8 \%(n=41)$ stated that they were undecided about the positive effects of the vaccine and did not want to get vaccinated, and $6.2 \%(n=29)$ stated that they thought that the vaccine would have negative effects/would be ineffective and did not want to get vaccinated (Table 2).

Scores from four different scales applied to participants are presented in Table 3.

The mean total score of the participants examined within the scope of the study from the COVID-19 Phobia Scale was $74.5 \pm 15.5(\min 22-\max 110)$, the mean score of the "worry" subscale was $33.5 \pm 8.5(\min 10-\max 50)$, the mean score of the "reassurance seeking/precaution" subscale was $24.6 \pm 4.9$ (min 7-max 35), the mean score of the "mood" subscale was $8.3 \pm 2.9(\min 3-\max 15)$, and the mean score of the "avoidance" subscale was $8.2 \pm 1.7(\min 2-\max 10)$ (Table 3$)$.

The mean total score of the Intolerance of Uncertainty Scale (IUS-12) was $38.4 \pm 9.7(\min 12-\max 60)$, the mean score of the "prospective anxiety" subscale was $23.2 \pm 5.4$ (min 7-max 35), and the mean score of the "debilitating anxiety" subscale was $15.2 \pm 5.0(\min 5-\max 25)$ (Table 3$)$.

The mean score of the Conspiracy Mentality Scale (CMS) applied to the participants was $34.0 \pm 8.8$ ( $\min 0-\max 50)$ whereas the mean Vaccine Conspiracy Beliefs Scale (VCBS) score was $21.2 \pm 12.6(\min 0-\max 50)$ (Table 3$)$. 
Table 1 Some descriptive characteristics of the participants

\begin{tabular}{|c|c|}
\hline & $(n=467)$ \\
\hline Age (years), mean $\pm \mathrm{SD}(\min -\max )$ & $35.8 \pm 9.1(18-67)$ \\
\hline \multicolumn{2}{|l|}{ Gender, $n(\%)$} \\
\hline Male & $206(44.1)$ \\
\hline Female & $261(55.9)$ \\
\hline \multicolumn{2}{|l|}{ Marital status, $n(\%)$} \\
\hline Married & $295(63.2)$ \\
\hline Single & $161(34.5)$ \\
\hline Other & $11(2.4)$ \\
\hline \multicolumn{2}{|l|}{ Child status, $n(\%)$} \\
\hline Yes & $244(52.2)$ \\
\hline No & $223(47.8)$ \\
\hline Number of children of those with children $(n=244)$, mean \pm SD $(\min -\max )$ & $1.7 \pm 0.8(1-4)$ \\
\hline \multicolumn{2}{|l|}{ Profession, $n(\%)$} \\
\hline Physician & $180(38.5)$ \\
\hline Teacher & $46(9.9)$ \\
\hline Assistant healthcare personnel & $44(9.4)$ \\
\hline Pharmaceutical representative & $26(5.6)$ \\
\hline Housewife & $20(4.3)$ \\
\hline Engineer & $19(4.1)$ \\
\hline School student & $14(3.0)$ \\
\hline Dentist & $13(2.8)$ \\
\hline Faculty member & $12(2.6)$ \\
\hline Not working & $11(2.4)$ \\
\hline Other & $82(17.6)$ \\
\hline \multicolumn{2}{|l|}{ Previous COVID-19 experience } \\
\hline Yes & $80(17.1)$ \\
\hline No & $387(82.9)$ \\
\hline \multicolumn{2}{|l|}{ Treatments administered to COVID-19 patients $(n=80)$} \\
\hline Outpatient treatment & $75(93.8)$ \\
\hline Inpatient treatment in hospital & $3(3.8)$ \\
\hline Inpatient treatment in ICU & $2(2.5)$ \\
\hline \multicolumn{2}{|l|}{ COVID-19 experience of a first-degree relative } \\
\hline Yes & $173(37.0)$ \\
\hline No & $294(63.0)$ \\
\hline \multicolumn{2}{|l|}{ Death of a first-degree relative or close friend due to COVID-19 } \\
\hline Yes & $63(13.5)$ \\
\hline No & $404(86.5)$ \\
\hline
\end{tabular}

$n$ number of individuals, $\%$ percent, mean mean, $S D$ standard deviation
The distribution of participants' descriptive characteristics according to their attitudes towards the COVID-19 vaccine is presented in Table 4 . There was a statistically significant difference between the participants' attitudes towards the COVID-19 vaccine in terms of age and gender $(p=0.003 ; p=0.002$, respectively). Post hoc binary
Table 2 Attitudes of participants towards COVID-19 vaccine

\begin{tabular}{ll}
\hline$(n=467)$ & $n(\%)$ \\
\hline Attitude towards COVID-19 vaccine & $206(44.1)$ \\
Trusts the positive effects of the vaccine and wants to get vaccinated & $191(40.9)$ \\
Unsure about the positive effects of the vaccine but wants to get vaccinated & $41(8.8)$ \\
Unsure about the positive effects of the vaccine and does not want to get vaccinated & $29(6.2)$ \\
Thinks the vaccine will have negative effects/will be ineffective and does not want to get & \\
$\quad$ vaccinated & \\
\hline
\end{tabular}

$n$ number of individuals, $\%$ percent 
Table 3 Scores of the scales applied to participants

\begin{tabular}{lc}
\hline$(n=467)$ & Mean \pm SD (min-max) \\
\hline COVID-19 Phobia Scale & \\
$\quad$ Anxiety & $33.5 \pm 8.5(10-50)$ \\
$\quad$ Reassurance seeking/precaution & $24.6 \pm 4.9(7-35)$ \\
$\quad$ Mood & $8.3 \pm 2.9(3-15)$ \\
Avoidance & $8.2 \pm 1.7(2-10)$ \\
$\quad$ Total & $74.5 \pm 15.5(22-110)$ \\
Intolerance of Uncertainty Scale 12 (IUS-12) & \\
$\quad$ Prospective anxiety & $23.2 \pm 5.4(7-35)$ \\
$\quad$ Debilitating anxiety & $15.2 \pm 5.0(5-25)$ \\
$\quad$ Total & $38.4 \pm 9.7(12-60)$ \\
Conspiracy Mentality Scale (CMS) & $34.0 \pm 8.8(0-50)$ \\
Vaccine Conspiracy Beliefs Scale (VCBS) & $21.2 \pm 12.6(0-50)$ \\
\hline
\end{tabular}

$n$ number of individuals, mean mean, SD standard deviation, IUS Intolerance of Uncertainty Scale, CMS Conspiracy Mentality Scale, VCBS Vaccine Conspiracy Beliefs Scale

comparisons showed that the significant difference in age was between "those who trusted the positive effects of the vaccine and wanted to get vaccinated" and "those who thought the vaccine would have negative effects/would be ineffective and did not want to get vaccinated." The age of those who thought the vaccine would have negative effects/ would be ineffective and did not want to get vaccinated was significantly lower compared to those who trusted the positive effects of the vaccine and wanted to get vaccinated. In addition, the percentage of men who trusted the positive effects of the vaccine and wanted to get vaccinated was significantly higher compared to the other attitude groups (Table 4). On the other hand, there were no statistically significant differences between participants' attitudes towards the COVID-19 vaccine in terms of marital status, child status, and the number of children of those with children $(p>0.05)$ (Table 4).

The distribution of some characteristics of participants related to COVID-19 according to their attitudes towards the COVID-19 vaccine is presented in Table 4. There was a statistically significant difference between participants' attitudes towards the COVID-19 vaccine in terms of a death of a first-degree relative or close friend due to COVID-19 $(p=0.017)$. Among those who thought the vaccine would have negative effects/would be ineffective and did not want to get vaccinated, the percentage of those with a first-degree relative or close friend that died due to COVID-19 was significantly higher compared to the other attitude groups

Table 4 Distribution of some descriptive characteristics of participants according to their attitudes towards COVID-19 vaccine

\begin{tabular}{|c|c|c|c|c|c|}
\hline & \multicolumn{4}{|c|}{ Attitude towards COVID-19 vaccine } & \multirow[t]{2}{*}{$p$} \\
\hline & Group I $(n=206)$ & Group II $(n=191)$ & Group III $(n=41)$ & Group IV $(n=29)$ & \\
\hline Age (years), mean $\pm \mathrm{SD}(\min -\max )$ & $36.9 \pm 8.6(22-65)$ & $35.8 \pm 9.3(19-67)$ & $32.5 \pm 9.5(18-61)$ & $32.0 \pm 8.0(21-47)^{\mathrm{a}}$ & $0.003 *$ \\
\hline \multicolumn{6}{|l|}{ Gender, $n(\%)$} \\
\hline Male & $110(53.4)$ & $65(34.0)$ & $18(43.9)$ & $13(44.8)$ & \multirow[t]{2}{*}{$0.002 *$} \\
\hline Female & $96(46.6)$ & $126(66.0)$ & $23(56.1)$ & $16(55.2)$ & \\
\hline \multicolumn{6}{|l|}{ Marital status, $n(\%)$} \\
\hline Married & $137(66.5)$ & $124(64.9)$ & $21(51.2)$ & $13(44.8)$ & \multirow[t]{3}{*}{0.224} \\
\hline Single & $65(31.6)$ & $62(32.5)$ & $19(46.3)$ & $15(51.7)$ & \\
\hline Other & $4(1.9)$ & $5(2.6)$ & $1(2.4)$ & $1(3.4)$ & \\
\hline Child presence, $n(\%)$ & $117(56.8)$ & $100(52.4)$ & $16(39.0)$ & $11(37.9)$ & 0.073 \\
\hline $\begin{array}{l}\text { Number of children of those with children, mean } \pm \text { SD } \\
(\text { min-max })\end{array}$ & $1.7 \pm 0.8(1-4)$ & $1.7 \pm 0.7(1.4)$ & $2.2 \pm 1.1(1-4)$ & $1.7 \pm 0.6(1-3)$ & 0.337 \\
\hline Previous COVID-19 experience & $36(17.5)$ & $28(14.7)$ & $8(19.5)$ & $8(27.6)$ & 0.357 \\
\hline \multicolumn{6}{|l|}{ Treatments administered to COVID-19 patients } \\
\hline Outpatient treatment & $34(94.4)$ & $27(96.4)$ & $6(75.0)$ & $8(100)$ & \multirow[t]{2}{*}{0.127} \\
\hline Inpatient treatment & $2(5.6)$ & $1(3.6)$ & $2(25.0)$ & 0 & \\
\hline COVID-19 experience of a first degree relative & $76(36.9)$ & $71(37.2)$ & $16(39.0)$ & $10(34.5)$ & 0.985 \\
\hline $\begin{array}{l}\text { Death of a first degree relative or close friend due to } \\
\text { COVID-19 }\end{array}$ & $18(8.7)$ & $30(15.7)$ & $7(17.1)$ & 8 (27.6) & $0.017 *$ \\
\hline
\end{tabular}

$n$ number of individuals, \% column percentage, mean mean, $S D$ standard deviation, Group I trusts the positive effects of the vaccine and wants to get vaccinated, Group II unsure about the positive effects of the vaccine but wants to get vaccinated, Group III unsure about the positive effects of the vaccine and does not want to get vaccinated, Group IV thinks the vaccine will have negative effects/will be ineffective and does not want to get vaccinated

$* p<0.05$

aPost hoc paired comparison revealed a significant difference with the "group I" group 
(Table 4). On the other hand, there were no statistically significant differences between participants' attitudes towards the COVID-19 vaccine in terms of previous COVID-19 experience, types of treatment administered to COVID-19 patients, and COVID-19 experience of a first-degree relative $(p>0.05)$ (Table 4).

The distribution of scale scores applied among participants' attitudes towards the COVID-19 vaccine is presented in Table 5. There was a statistically significant difference between participants' attitudes towards the COVID-19 vaccine in terms of the COVID-19 Phobia Scale total score $(p=0.002)$. Post hoc binary comparisons showed that the significant difference was between those who were undecided about the positive effects of the vaccine but wanted to get vaccinated (group II) and those who were undecided about the positive effects of the vaccine and did not want to get vaccinated (group III) and those who thought that the vaccine would have negative effects/would have negative effects and did not want to get vaccinated (group IV). The total COVID-19 Phobia Scale score of those who were undecided about the positive effects of the vaccine but wanted to get vaccinated (group II) was significantly higher compared to those who were undecided about the positive effects of the vaccine and did not want to get vaccinated (group III) and those who thought the vaccine would have negative effects/ would be ineffective and did not want to get vaccinated (group IV) (Table 5).

There was a statistically significant difference between participants' attitudes towards the COVID-19 vaccine in terms of the COVID-19 Phobia Scale "anxiety" subscale score $(p=0.007)$. Post hoc binary comparisons showed that the significant difference was between those who were undecided about the positive effects of the vaccine but wanted to get vaccinated (group II) and those who were undecided about the positive effects of the vaccine and did not want to get vaccinated (group III). The COVID-19 Phobia Scale "anxiety" subscale score of those who were undecided about the positive effects of the vaccine but wanted to get vaccinated (group II) was significantly higher compared to those who were undecided about the positive effects of the vaccine and did not want to get vaccinated (group III) (Table 5).

There was a statistically significant difference between participants' attitudes towards the COVID-19 vaccine in terms of the COVID-19 Phobia Scale "reassurance seeking" subscale score $(p<0.001)$. Post hoc binary comparisons showed that the signifivaccinated (group II). The COVID-19 phobia "reassurance seeking" subscale score of those who thought the vaccine would have negative effects/ would be ineffective and did not want to get vaccinated (group IV) was significantly lower compared to those who trusted the positive effects of the vaccine and wanted to get vaccinated (group I) and those who were undecided about the poscant difference was between those who thought the vaccine would have negative effects/would have negative effects and did not want to get vaccinated (group IV) and those who trusted the positive effects of the vaccine and wanted to get vaccinated (group I) and those who were undecided about the positive effects of the vaccine and wanted

Table 5 Distribution of scores of scales applied among participants' attitudes towards COVID-19 vaccine

\begin{tabular}{|c|c|c|c|c|c|}
\hline & \multicolumn{4}{|c|}{ Attitude towards COVID-19 Vaccine } & \multirow[t]{2}{*}{$p$} \\
\hline & Group-I $(n=206)$ & Group-II $(n=191)$ & Group-III $(n=41)$ & Group-IV $(n=29)$ & \\
\hline \multicolumn{6}{|l|}{ COVID-19 Phobia Scale } \\
\hline Anxiety & $33.3 \pm 8.3(10-50)$ & $34.9 \pm 7.9(12-50)$ & $30.3 \pm 10.1(10-49)$ & $29.9 \pm 9.8(10-47)$ & $0.007 *$ \\
\hline Reassurance seeking & $24.5 \pm 4.6(7-35)$ & $25.5 \pm 4.4(10-35)$ & $22.8 \pm 5.7(10-33)$ & $21.0 \pm 6.6(7-35)$ & $<0.001 *$ \\
\hline Mood & $8.1 \pm 2.8(3-15)$ & $8.6 \pm 2.9(3-15)$ & $8.0 \pm 3.1(3-14)$ & $7.7 \pm 3.4(3-14)$ & 0.208 \\
\hline Avoidance & $8.2 \pm 1.6(2-10)$ & $8.3 \pm 1.6(2-10)$ & $8.2 \pm 1.6(4-10)$ & $7.2 \pm 2.2(2-10)$ & 0.058 \\
\hline Total & $74.2 \pm 14.7(22-110)$ & $77.3 \pm 14.1(34-108)$ & $69.4 \pm 18.5(35-104)$ & $65.8 \pm 20.0(22-98)$ & $0.002 *$ \\
\hline \multicolumn{6}{|l|}{ IUS-12 } \\
\hline Prospective anxiety & $22.7 \pm 5.6(7-35)$ & $23.8 \pm 5.1(8-35)$ & $22.9 \pm 5.0(11-33)$ & $22.8 \pm 6.2(7-35)$ & 0.361 \\
\hline Debilitating anxiety & $14.8 \pm 4.8(5-25)$ & $15.8 \pm 5.0(5-25)$ & $15.1 \pm 5.4(5-25)$ & $14.9 \pm 5.3(5-22)$ & 0.231 \\
\hline Total & $37.4 \pm 9.8(12-60)$ & $39.6 \pm 9.4(14-60)$ & $38.0 \pm 9.5(18-56)$ & $37.7 \pm 10.6(12-56)$ & 0.229 \\
\hline CMS & $31.8 \pm 8.7(0-50)$ & $35.3 \pm 7.9(9-50)$ & $37.6 \pm 9.2(13-50)$ & $36.8 \pm 10.3(9-50)$ & $<0.001 *$ \\
\hline VCBS & $15.5 \pm 11.2(0-50)$ & $24.1 \pm 11.0(0-50)$ & $27.4 \pm 11.5(0-50)$ & $34.4 \pm 12.6(0-50)$ & $<0.001 *$ \\
\hline
\end{tabular}

Variables were presented as "mean \pm standard deviation (minimum-maximum)"

$n$ number of individuals, IUS Intolerance of Uncertainty Scale, CMS Conspiracy mentality scale, VCBS Vaccine Conspiracy Beliefs Scale, Group I trusts the positive effects of the vaccine and wants to get vaccinated, Group II unsure about the positive effects of the vaccine but wants to get vaccinated, Group III unsure about the positive effects of the vaccine and does not want to get vaccinated, Group IV thinks the vaccine will have negative effects/will be ineffective and does not want to get vaccinated

${ }^{*} p<0.05$ 
to get vaccinated (group II) and those who were undecided about the positive effects of the vaccine and did not want to get vaccinated (group III) and those who were undecided about the negative effects of the vaccine but wanted to get itive effects of the vaccine and wanted to get vaccinated (group II). In addition, the COVID-19 phobia "reassurance seeking" subscale score of those who were undecided about the positive effects of the vaccine and did not want to get vaccinated (group III) was significantly lower compared to those who were undecided about the positive effects of the vaccine but wanted to get vaccinated (group II) (Table 5).

On the other hand, there were no statistically significant differences between participants' attitudes towards the COVID-19 vaccine in terms of COVID-19 phobia "mood" and "avoidance" subscale scores $(p>0.05)$ (Table 5).

There was a statistically significant difference between participants' attitudes towards the COVID-19 vaccine in terms of CMS and VCBS scores ( $p<0.001$ for both). Post hoc binary comparisons showed that the significant differences were caused by those who trusted the positive effects of the vaccine and wanted to get vaccinated (group I). The CMS and VCBS scores of those who trusted the positive effects of the vaccine and wanted to get vaccinated (group I) were significantly lower compared to those who exhibited other attitudes (Table 5).

There were no statistically significant differences between participants' attitudes towards the COVID-19 vaccine in terms of IUS-12 total score and "prospective anxiety" and "debilitating anxiety" subscale scores $(p>0.05)$ (Table 5).

The relationship between the scales applied to the participants included in the study is shown in Table 6.

There was a positive, moderate, and weak statistically significant correlation between participants' total COVID19 Phobia Scale score and IUS-12 total score $(r=0.44)$, prospective anxiety $(r=0.42)$, and debilitating anxiety $(r=0.40)$ subscale scores, and between COVID-19 Phobia Scale total score and CMS $(r=0.17)$ and VCBS $(r=0.19)$ scores $(p<0.05)$ (Table 6).

There was a positive and weak statistically significant correlation between the participants' total IUS-12 score and CMS $(r=0.24)$ and VCBS $(r=0.24)$ scores $(p<0.05)$ (Table 6).

A positive, moderate, and statistically significant relationship was found between the CMS score and VCBS score of the participants $(r=0.46 ; p<0.05)$ (Table 6$)$.

While a positive, weak, statistically significant relationship was found between the age of the participants examined within the scope of the study and the COVID19 Phobia Scale "reassurance seeking $(r=0.14)$ " and "avoidance $(r=0.12)$ " subscale scores, no statistically significant relationship was found between the age of the participants and all other scale and subscale scores $(p>0.05)$ (Table 6).

Table 6 The relationship between the scales applied to the participants

\begin{tabular}{|c|c|c|c|c|c|c|}
\hline \multirow[t]{2}{*}{$(n=467)$} & \multirow[t]{2}{*}{ Age } & \multicolumn{3}{|l|}{ IUS-12 } & \multirow[t]{2}{*}{ CMS } & \multirow[t]{2}{*}{ VCBS } \\
\hline & & Prospective Anxiety & Debilitating Anxiety & Total & & \\
\hline \multicolumn{7}{|l|}{ COVID-19 PHOBIA } \\
\hline Anxiety & 0.038 & $0.384 * *$ & $0.370 * *$ & $0.404 * *$ & $0.150 * *$ & $0.173 * *$ \\
\hline Reassurance Seeking & $0.139 * *$ & $0.316^{* *}$ & $0.299 * *$ & $0.331 * *$ & $0.137 * *$ & $0.208 * *$ \\
\hline Mood & -0.007 & $0.375^{* *}$ & $0.345^{* *}$ & $0.387 * *$ & $0.111^{*}$ & $0.113^{*}$ \\
\hline Avoidance & $0.124 * *$ & $0.306^{* *}$ & $0.267 * *$ & $0.309 * *$ & $0.141 * *$ & 0.027 \\
\hline Total & 0.072 & $0.421 * *$ & $0.405^{* *}$ & $0.444 * *$ & $0.166^{* *}$ & $0.188 * *$ \\
\hline \multicolumn{7}{|l|}{ IUS-12 } \\
\hline Prospective Anxiety & -0.032 & 1.000 & $0.717 * *$ & $0.923 * *$ & $0.238 * *$ & $0.203 * *$ \\
\hline Debilitating Anxiety & -0.057 & $0.717 * *$ & 1.000 & $0.925^{* *}$ & $0.212 * *$ & $0.255^{* *}$ \\
\hline Total & -0.047 & $0.923 * *$ & $0.925 * *$ & 1.000 & $0.242 * *$ & $0.244 * *$ \\
\hline CMS & -0.028 & $0.238 * *$ & $0.212 * *$ & $0.242 * *$ & 1.000 & $0.465^{* *}$ \\
\hline VCBS & 0.044 & $0.203 * *$ & $0.255^{* *}$ & $0.244 * *$ & $0.465 * *$ & 1.000 \\
\hline
\end{tabular}

Variables are presented with Spearman's correlation coefficient

$n$ number of individuals, IUS Intolerance of Uncertainty Scale, CMS Conspiracy Mentality Scale, VCBS Vaccine Conspiracy Beliefs Scale

$* p<0.05 ; * * p<0.01$ 


\section{Discussion}

Two of our initial three hypotheses were confirmed according to the results of our study. In other words, we could not confirm the hypothesis that individuals who have a low tolerance to uncertainty will have increased coronavirus vaccine hesitancy/rejection. We found a positive correlation between the belief in conspiracy theories, which is our second hypothesis, and vaccine hesitancy. Our third hypothesis confirmed that individuals with low fear of COVID-19 would hesitate about vaccination.

One of the most striking points of our results was that $15 \%$ of respondents had a negative attitude towards vaccines. $44.1 \%$ stated that they trusted the vaccines' effects and would get vaccinated, and $6.2 \%$ stated that the vaccine would have negative effects or would be ineffective or would not get vaccinated. Three percent of the participants in Turkey and the UK rejected the vaccine, $31 \%$ in Turkey, and $14 \%$ in the UK stated that they were undecided about getting vaccinated in another study conducted with 5024 people in the two countries [18]. These rates appear as a negative scenario about the process of vaccine administration, which appears to be the only way out of the pandemic in the social sense. We found that women had more negative attitudes towards vaccines when evaluated in terms of gender. The negative attitudes towards vaccines in women were also consistent with a number of studies in the literature [18-21]. This may be related to the mortality rates of the disease in the male gender [21]. In addition, women are more likely to make health-related decisions for their children, as well as for themselves, so they may be investigating further health-related information and may be more likely to be exposed to inaccurate information [22]. Increased information search can be an important factor given the information pollution that courageously spreads through social media. It was seen that anti-vaccine individuals shared more misleading claims on social media, and vaccine advocates were not prone to less reliable claims in a study evaluating 2000 Twitter accounts related to vaccine discourse [23]. It was shown in the same study that they also tweeted about conservative politics and conspiracy theories in their anti-vaccine accounts. The majority of social media users in Turkey are young people. This information is useful in explaining that the age of the "completely anti-vaccine" group, which is one of our study results, is significantly younger. It is consistent with the knowledge of young age and negative attitudes towards vaccines in the literature [24].

It was reported that $13.9 \%$ of participants would not get vaccinated or had low intentions about getting vaccinated in a previous study conducted with 735 university students [25]. No difference was found between the students studying in the departments related to the healthcare industry and those studying in other departments in terms of vaccine attitude in this study. Interpreting vaccine attitudes only through health information may make it difficult to understand the problem in this sense. Understanding whether there is a difference in these people's access to information or in distinguishing the accurate information will be helpful in understanding vaccine attitudes. The relationship between anti-vaccine individuals and conspiracy theories can be enlightening in this respect.

The group, which was "completely anti-vaccine," received lower scores on the COVID-19 Phobia Scale when we evaluated the results of our study on the scales. It may be thought that these people are less worried about COVID-19 compared to others because they underestimate the possible negative effects of COVID-19 and think it is an "exaggerated scenario" related to politics or the media. Previous studies have reported that belief in the natural origin of coronavirus is a factor that increases vaccine acceptance [18]. Believing that the virus is an artificial product may lead to underestimating pandemic situations and may therefore cause a negative attitude towards vaccines.

Anxiety and psychological processes associated with the pandemic may affect health behaviors and search for treatment $[26,27]$. It can also be said that COVID-19 causes an emotionally burdensome process. This burdensome process and anti-vaccine discourses that emerge due to their nature may increase uncertainty and confusion [28]. Previous studies have reported that worries about vaccine safety, side effects, and rapid development may be associated with negative vaccination attitudes [29]. Negative emotions have been reported to be associated with vaccine risk perceptions and vaccine attitudes [30]. It will be important to address emotional processes and provide accurate and safe information to overcome negative attitudes towards vaccines [30]. Previous studies have indicated that the biggest worry about vaccines may be related to the quality control and side effect profiles of a COVID-19 vaccine [21]. Uncertainties about the vaccine and possible conspiracy theories can be expected to affect the vaccine administration in this sense adversely. Vaccine hesitancy has also been associated with conspiracy, paranoia, and religious beliefs [31-33]. In addition, distrust towards authorized persons was evaluated related to vaccine rejection [34-36].

The Conspiracy Mentality Scale scores and the total scores given by this group to the items in the questionnaire about the vaccine conspiracy were significantly higher at the same time. Vaccine hesitancy/resistance was found to be $31-35 \%$, respectively, in a previous study of approximately 3000 people in the UK and Ireland [24]. This study reported that people who experienced vaccine resistance/ hesitancy related to a COVID-19 vaccine were less likely to 
obtain information about the pandemic from reliable sources (such as scientists, healthcare professionals, managers), and their distrust towards these sources of information (conspiracy perspectives) was higher. The relationship between "anti-vaccine" attitudes and distrust towards authority was emphasized, and it was emphasized as an expression of the "anti-authority" attitudes of these people [24]. It may be important for people from different opinions and groups to support vaccine studies as a solution to their attitudes. The importance of religious leaders' support for vaccine studies has been emphasized in previous studies [37].

Anti-vaccine websites were examined, and speculations were found on human rights violations and possible side effects of vaccines on 76-88\% of them in previous studies $[38,39]$. The belief that the coronavirus is produced in a laboratory and spread to the world in a planned manner for certain reasons may emerge as an important theory, especially for minds prone to conspiracy theories [18]. It is important to plan the studies on vaccine hesitancy by taking into account these conspiracy theories [28].

A form containing five conspiracy theories that are most on the agenda related to vaccines in Turkey was also created by the study team in parallel with the conspiracy mentality scale in our study. We also found a significant correlation with the conspiracy mentality scale in the scores of this form. Similarly, there was a significant difference in the scores of this form in terms of vaccine attitudes. In other words, people's general beliefs in conspiracy theories may also be reflected in their ideas about the vaccine. It would be useful to look for ways to spread accurate information about the vaccine in a healthier way in this case.

\section{Conclusion}

Vaccine hesitancy is an important public health problem, and it puts public health at risk, especially during the epidemic period we live in. Therefore, it is important to understand the psychological factors involved in vaccine hesitancy. It would be useful to look for ways to spread accurate information about the vaccine in a healthier way in this case.

\section{References}

1. WHO (2020) Coronavirus disease (COVID-19) situation report 130. World Health Organization. Available from: https://www.who. int/docs/default-source/coronaviruse/situation-reports/20200529covid-19-sitrep-130.pdf?sfvrsn=bf7e7f0c_4 [Accessed 30 May]

2. Anderson RM, Heesterbeek H, Klinkenberg D et al (2020) How will country-based mitigation measures influence the course of the COVID-19 epidemic? The lancet 395(10228):931-934

3. Godlee F (2019) What should we do about vaccine hesitancy?: British Medical Journal Publishing Group 2019:365. https://doi. org/10.1136/bmj.14044
4. Larson HJ, Jarrett C, Eckersberger E et al (2014) Understanding vaccine hesitancy around vaccines and vaccination from a global perspective: a systematic review of published literature, 2007-2012. Vaccine 32(19):2150-2159

5. Hornsey MJ, Fielding KS (2017) Attitude roots and Jiu Jitsu persuasion: understanding and overcoming the motivated rejection of science. Am Psychol 72(5):459-473

6. Leventhal H, Brissette I, Leventhal EA (2003) The commonsense model of self-regulation of health and illness. The selfregulation of health and illness behaviour 1:42-65

7. Rieger MO (2020) Triggering altruism increases the willingness to get vaccinated against COVID-19. Soc Health Behav $3(3): 78-82$

8. Johnson MO (2000) Personality correlates of HIV vaccine trial participation. Personality Individ Differ 29(3):459-467

9. Hornsey MJ, Harris EA, Fielding KS (2018) The psychological roots of anti-vaccination attitudes: a 24-nation investigation. Health Psychol 37(4):307-315

10. Kennedy J (2019) Populist politics and vaccine hesitancy in Western Europe: an analysis of national-level data. Eur J Pub Health 29(3):512-516

11. Dolan M, Fullam R (2004) Theory of mind and mentalizing ability in antisocial personality disorders with and without psychopathy. Cambridge University Press Psychological Medicine 34(6):1093-1102

12. Habersaat KB, Jackson C (2020) Understanding vaccine acceptance and demand - and ways to increase them. Bundesgesundheitsblatt Gesundheitsforschung Gesundheitsschutz 63(1):32-39

13. Sarıçam H, Erguvan FM, Akın A et al (2014) The Turkish short version of the Intolerance of Uncertanity (IUS-12) Scale: the study of validity and reliability. Route Educational and Social Science Journal 1(3):148-157

14. Bruder M, Manstead ASR (2009) Komplo teorileri üzerine bir anket. http://www.conspiracytheory.martinbruder.com/tr

15. Bruder M, Haffke P, Neave N et al (2013) Measuring individual differences in generic beliefs in conspiracy theories across cultures: Conspiracy Mentality Questionnaire. Front Psychol 4:225. https://doi.org/10.3389/fpsyg.2013.00225

16. Başerdem U, Doğulu C (2019) Bilim Karşıtlı̆̆ ve ölüm: Bilim inkarının ve komplo inancının dehşet yönetimi açısından incelenmesi. Başkent Üniversitesi Sosyal Bilimler Enstitüsü Psikoloji AD Sosyal Psikoloji Yüksek Lisans Tezi

17. Dilbaz N, Noyan OC, Alpar G et al (2020) Development of the COVID-19 Phobia Scale: validity and reliability study. J Neurobehavioral Sci 7(3)

18. Salali GD, Uysal MS (2020) COVID-19 vaccine hesitancy is associated with beliefs on the origin of the novel coronavirus in the UK and Turkey. Psychol Med 1-3

19. Pulcini C, Massin S, Launay O et al (2013) Factors associated with vaccination for hepatitis $\mathrm{B}$, pertussis, seasonal and pandemic influenza among French general practitioners: a 2010 survey. Vaccine 31(37):3943-3949

20. Flanagan KL, Fink AL, Plebanski M et al (2017) Sex and gender differences in the outcomes of vaccination over the life course. Annu Rev Cell Dev Biol 33:577-599

21. Dror AA, Eisenbach N, Taiber S, Morozov NG et al (2020) Vaccine hesitancy: the next challenge in the fight against COVID-19. Eur J Epidemiol 35(8):775-779

22. Smith N, Graham T (2019) Mapping the anti-vaccination movement on Facebook. Inf Commun Soc 22(9):1310-1327

23. Jamison AM, Quinn SC, Freimuth VS (2019) You don't trust a government vaccine: narratives of institutional trust and influenza vaccination among African American and white adults. Soc Sci Med 221:87-94

24. Murphy J, Vallières F, Bentall RP et al (2021) Psychological characteristics associated with COVID-19 vaccine hesitancy 
and resistance in Ireland and the United Kingdom. Nat Commun 12(1):1-15

25. Barello S, Nania T, Dellafiore F et al (2020) 'Vaccine hesitancy' among university students in Italy during the COVID-19 pandemic. Eur J Epidemiol 35(8):781-783

26. Jungmann SM, Witthöft M (2020) Health anxiety, cyberchondria, and coping in the current COVID-19 pandemic: Which factors are related to coronavirus anxiety? J Anxiety Disord 73:102239

27. Morgul E, Bener A, Atak M et al (2020) COVID-19 pandemic and psychological fatigue in Turkey. Int J Soc Psychiatry

28. Chou W-YS, Budenz A (2020) Considering emotion in COVID-19 vaccine communication: addressing vaccine hesitancy and fostering vaccine confidence. Health Commun 35(14):1718-1722

29. Fisher KA, Bloomstone SJ, Walder J et al (2020) Attitudes toward a potential SARS-CoV-2 vaccine: a survey of US adults. Ann Intern Med 173(12):964-973

30. Betsch C, Ulshöfer C, Renkewitz F et al (2011) The influence of narrative $\mathrm{v}$. statistical information on perceiving vaccination risks. Med Decis Making 31(5):742-753

31. Murakami H, Kobayashi M, Hachiya M, Khan ZS, Hassan SQ, Sakurada S (2014) Refusal of oral polio vaccine in northwestern Pakistan: a qualitative and quantitative study. Vaccine 32(12):1382-1387
32. McHale P, Keenan A, Ghebrehewet S (2016) Reasons for measles cases not being vaccinated with MMR: investigation into parents' and carers' views following a large measles outbreak. Epidemiol Infect 144(4):870-875

33. Hornsey MJ, Harris EA, Fielding KS (2018) The psychological roots of anti-vaccination attitudes: A 24-nation investigation. Health Psychol 37(4):307

34. Mesch GS, Schwirian KP (2015) Social and political determinants of vaccine hesitancy: Lessons learned from the H1N1 pandemic of 2009-2010. Am J Infect Control 43(11): 1161-1165

35. Jamison AM, Quinn SC, Freimuth VS (2019) You don't trust a government vaccine: Narratives of institutional trust and influenza vaccination among African American and white adults. Soc Sci Med 221:87-94

36. Kennedy J (2019) Populist politics and vaccine hesitancy in Western Europe: an analysis of national-level data. Eur J Public Health 29(3):512-516

37. Zarocostas J (2004) UNICEF taps religious leaders in vaccination push. The Lancet 363(9422): 1709

38. Kata A (2010) A postmodern Pandora's box: anti-vaccination misinformation on the Internet. Vaccine 28(7):1709-1716

39. Bean SJ (2011) Emerging and continuing trends in vaccine opposition website content. Vaccine 29(10):1874-1880 